\title{
In situ HRTEM of a Catalyst Using a Nanoreactor at 1 Bar
}

\author{
S.B. Vendelbo*, J.F. Creemer**, S. Helveg***, B. Morana**, L. Mele**, A.M. Molenbroek***,
} P.M. Sarro**, H.W. Zandbergen**** and P.J. Kooyman*

*ChemE, Delft University of Technology, Julianalaan 136, 2628 BL Delft, The Netherlands

**DIMES-ECTM, Delft University of Technology, P.O. Box 5053, 2600 GB Delft, The

Netherlands

***Haldor Topsøe A/S, Nymøllevej 55, DK-2800 Kgs. Lyngby, Denmark

****Kavli Institute of Nanoscience, HREM, Delft University of Technology, P.O. Box 5046, 2600

GA Delft, The Netherlands

\section{Introduction}

In situ transmission electron microscopy is a powerful technique for atomic-scale imaging of nanomaterials, e.g. heterogeneous catalysts, during exposure to reactive gas environments [1]. Today, atomic-resolution in situ TEM is performed at pressures of up to about 10 mbar and temperatures of up to about $800^{\circ} \mathrm{C}$ [2-3]. However, it is important to apply these in situ TEM results with caution. Gas pressures in the mbar-region are much lower than the ambient pressures of 1 bar at which many catalysts find technological application. Because the state and properties of catalytic materials can depend strongly on their environment, it is desirable to have instruments for atomicscale imaging at ambient pressures [4]. Here we report on a nanoreactor that enables atomic-scale imaging of a $\mathrm{Cu} / \mathrm{ZnO}$ methanol synthesis catalyst at 1 bar gas pressures and elevated temperatures [5-7].

\section{Materials and Methods}

The high pressure is achieved by miniaturizing the gas volume and heater into a microelectromechanical system (MEMS) that fits into a normal TEM (Philips/FEI Company). Figure la shows a schematic of the nanoreactor. It consists of a gas inlet and outlet which are connected through a narrow gas channel. In the middle of this is a membrane which has several $10 \mathrm{~nm}$ thin windows etched out. These windows are transparent to high energy electrons. The spiral seen in figure $1 \mathrm{c}$ is the heater of the nanoreactor. This consists of a platinum film through which a current is passed, the resistivity of the thin film is used as a measure of the temperature.

\section{Results and Discussion}

The nanoreactor's performance is demonstrated by in situ HRTEM of a $\mathrm{Cu} / \mathrm{ZnO}$ methanol synthesis catalyst during exposure to 1.2 bar of $\mathrm{H}_{2}$ at temperatures up to $500{ }^{\circ} \mathrm{C}$. By the time-resolved imaging, dynamic insight into the reduction process and formation of $\mathrm{Cu}$ nanoparticles is obtained. Moreover, the structure of the nanocatalyst is resolved with atomic-scale resolution at the 1 bar reaction conditions.

\section{Significance}

We present a nanoreactor to do in situ HRTEM at conditions which are relevant for catalysis and anticipate that this approach will generate new insights into a variety of nanocatalysts and their interactions with ambient environments. 


\section{References}

1. P.L. Hansen, S. Helveg and A.K. Datye, Adv. Catal. 50, 77 (2006).

2. E.D. Boyes, P.L. Gai, Ultramicroscopy 67, 219 (1997).

3. S. Giorgio, S. Sao Joao, S. Nietsche, D. Chaudanson, G. Sitja, C.R. Henry, Ultramicroscopy 106, 503 (2006).

4. N.I. Jaeger, Science 293, 1601 (2001).

5. J.F. Creemer, S. Helveg, G.H. Hoveling, S. Ullmann, A.M. Molenbroek, P.M. Sarro, H.W. Zandbergen, Ultramicroscopy 108, 993-998 (2008).

6. J. F. Creemer, S. Helveg, P.J. Kooyman, A.M. Molenbroek, H.W. Zandbergen, and P.M. Sarro, Journal of Microelectromechanical Systems, IEEE Early Access, Issue 99, 1-11(2010).

7. L. Mele, F. Santagata, G. Pandraud, B. Morana, F. D. Tichelaar, J. F. Creemer and P. M. Sarro, J. Micromech. Microeng. 20085040 (2010)

a

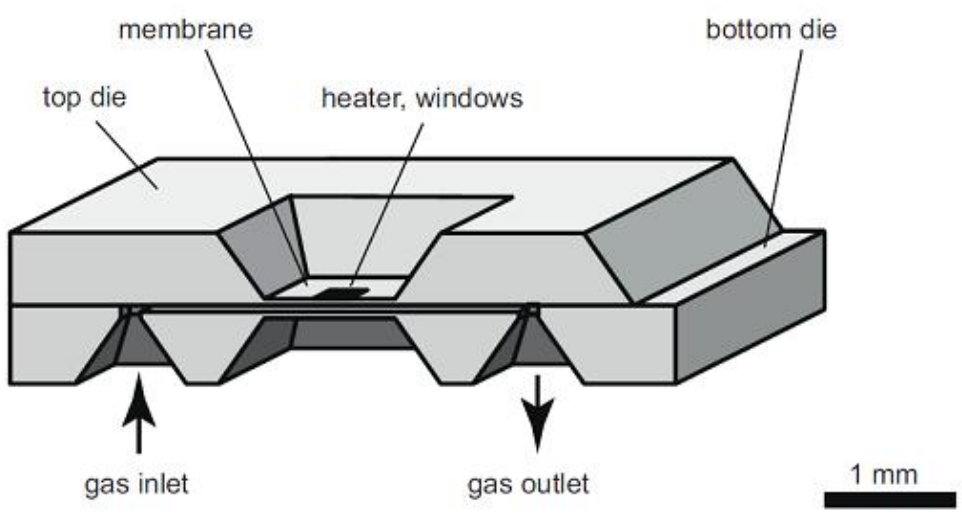

b

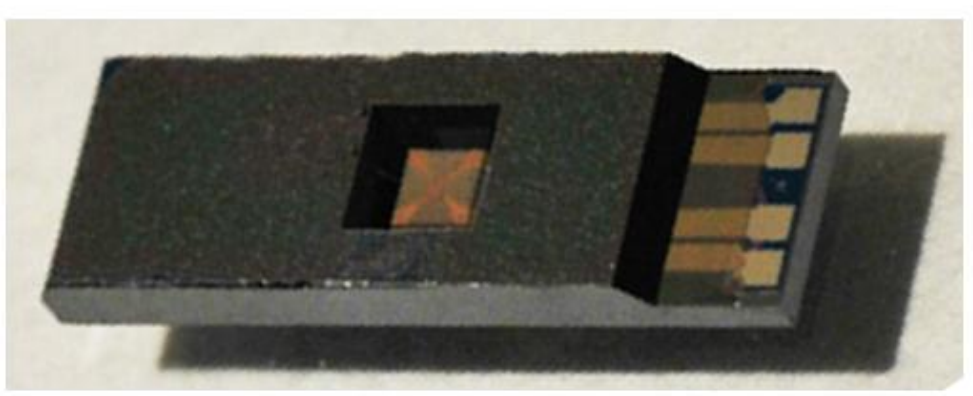

C

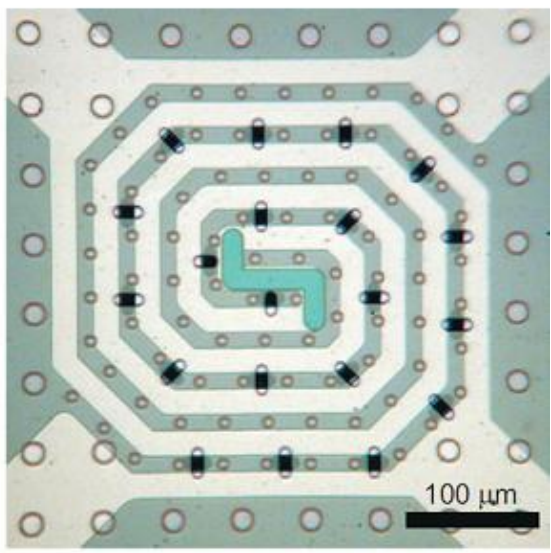

d

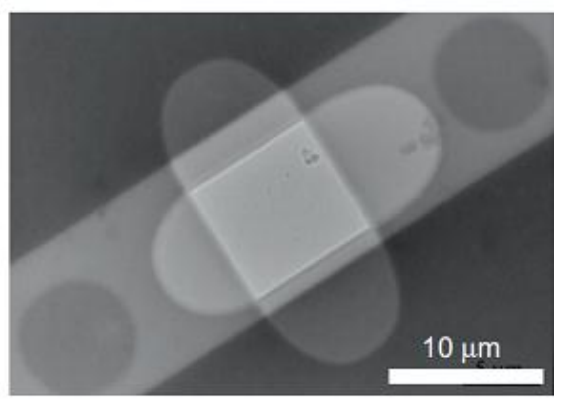

Figure 1. (a) Schematic cross-section of the nanoreactor. (b) Optical image of the nanoreactor. (c) Optical close-up of the nanoreactor membrane. The bright spiral is the heater. The small ovaloids are the electron-transparent windows. (d) A low-magnification TEM image of a pair of superimposed 10 $\mathrm{nm}$ thick windows creating highly electron-transparent areas for HRTEM. 